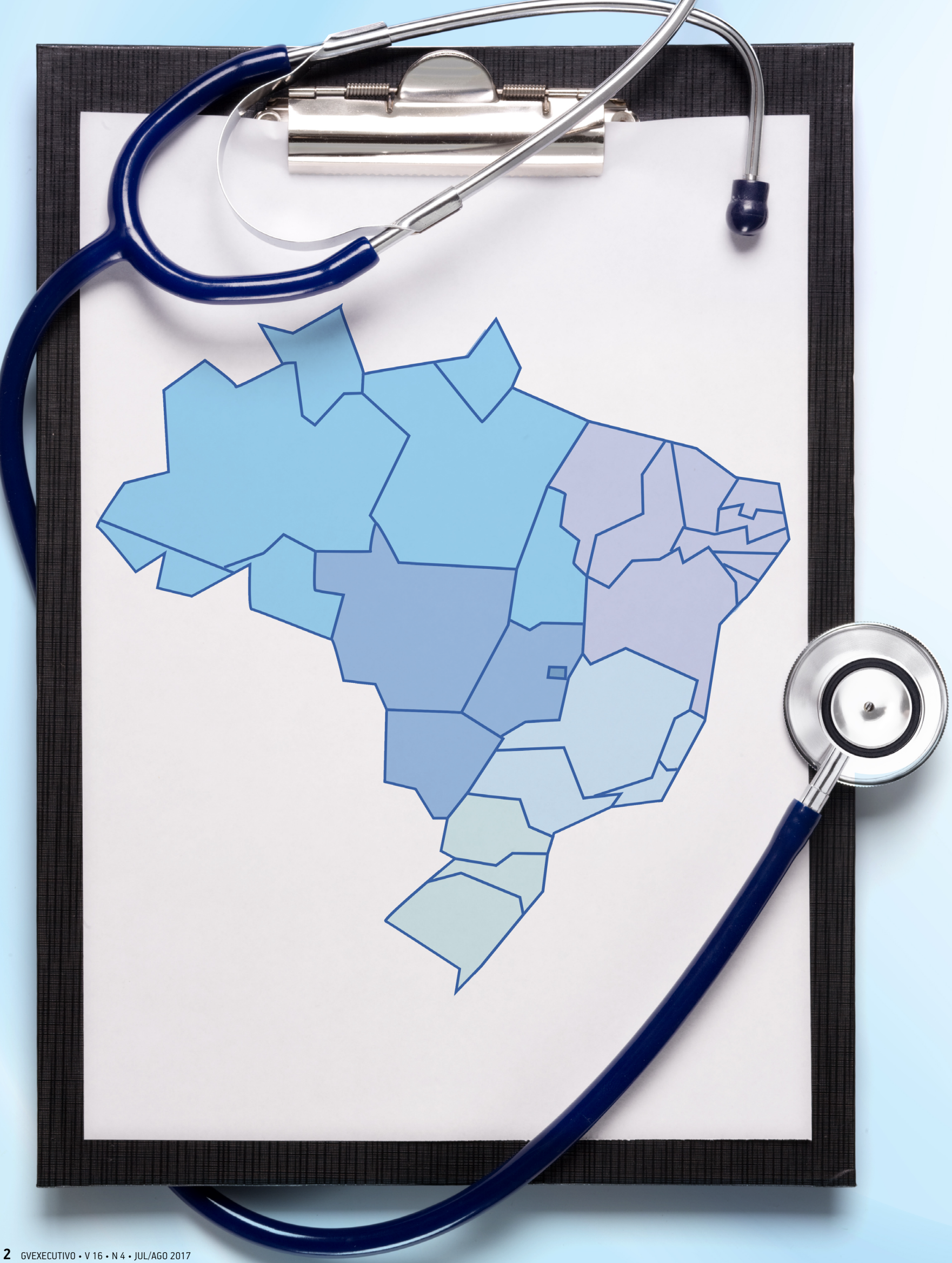




\section{UM DIAGNÓSTICO DA SAÚDE NO BRASIL}

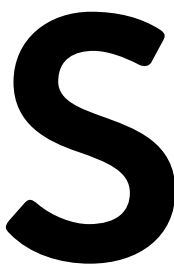

aúde é um tema complexo que desperta nosso interesse e impacta as organizações e a sociedade. No século XXI, adoecemos diferentemente em comparação aos séculos anteriores. Na atual "sociedade do cansaço", conforme bem define o filósofo Byung-Chul Han, o esgotamento toma conta das pessoas. A autoexigência pelo bom desempenho a qualquer custo faz com que se tornem frágeis mental e fisicamente.

No especial sobre gestão em saúde desta edição fica evidente que o crescente arsenal de tecnologias caras e intensivas será insuficiente para dar conta desse desafio. Como revela o artigo de Alberto José Ogata e Ana Maria Malik, é necessário unir esforços em diferentes áreas, nos setores público e privado, para conferir uma atenção integrada a cada indivíduo. As organizações de saúde no Brasil precisam desenvolver sistemas de gestão eficientes e interconectados. As empresas devem cuidar de seus funcionários. Saúde é, definitivamente, um tema de todos nós.

Assim, este número reúne especialistas, professores, pesquisadores e gestores que abordam, por diferentes perspectivas, as questões essenciais para a gestão da saúde no país. O primeiro artigo, de Gonzalo Vecina Neto e Ana Maria Malik, Tendências na gestão da saúde, detalha o impacto da Tecnologia da Informação na administração da saúde, em diagnósticos, em métodos de gestão ou no empoderamento dos pacientes. Mais do que isso, afirmam os autores, o Brasil precisa de um sistema de atendimento universal. O texto de Wilson Rezende, O mercado de clínicas não é mais o mesmo, aponta para um setor em transformação, especialmente no que se refere a clínicas de pequeno e médio portes: se forem eficientes, viram objeto de desejo de fundos de investimento; se não forem, correm o risco de desaparecer do mercado. No artigo A cura está nos médicos de família, Luiz Fernando Nicz mostra que os sistemas de saúde no Brasil são fragmentados e defende que o país teria muito a ganhar inspirando-se em sistemas de outras nações, apoiados no modelo de clínicas que funcionam como referência aos pacientes. No texto Nova administração nos hospitais públicos, Renilson Rehem alerta para a necessidade de parcerias com organizações sociais para a gestão eficiente dos hospitais. O trabalho de Laura Schiesari discute a importância do Cuidado com o paciente. Afinal, a boa administração deve beneficiar o usuário final do sistema. Além disso, uma seção especial com especialistas de diferentes setores (hospitais públicos e privados e empresas de saúde) revela as condições essenciais para atuar na gestão da saúde. Esperamos que esta edição possa contribuir para a melhoria do setor no país e para a saúde de todos os brasileiros.

Apresentamos também uma entrevista com Antonio José Rodrigues Pereira, superintendente do Hospital das Clínicas de São Paulo, o maior complexo hospitalar da América Latina. Ele fala sobre o Sistema Único de Saúde (SUS), os desafios da saúde no Brasil e ressalta a importância de público e privado caminharem juntos.

Completam a edição as colunas de Amon Narciso de Barros, sobre o assédio moral nas empresas em tempos de crise econômica; Marco Antonio Carvalho Teixeira, sobre como, apesar da crise política, precisamos da política para superar os impasses atuais; Samy Dana, a respeito da tendência de nos apegarmos a bens materiais; e Paulo Sandroni, que aborda o panorama da política econômica brasileira.

A $G V$-executivo reitera sua missão de disseminar dados de pesquisas aplicadas que possam ter impacto na gestão das organizações, em consonância com a missão da Fundação Getulio Vargas de contribuir para o desenvolvimento do Brasil.

Boa leitura.

Maria José Tonelli - Editora chefe

Adriana Wilner - Editora adjunta 